\title{
BMJ Open Mixed-methods assessment of health and mental health characteristics and barriers to healthcare for Ebola survivors in Beni, Butembo and Katwa health zones of the Democratic Republic of Congo
}

\author{
Lynn Lieberman Lawry (10 , ${ }^{1}$ Nancy Stroupe Kannappan, ${ }^{2}$ Covadonga Canteli, ${ }^{3}$ \\ William Clemmer ${ }^{4}$
}

To cite: Lawry LL, Stroupe Kannappan N, Canteli C, et al. Mixed-methods assessment of health and mental health characteristics and barriers to healthcare for Ebola survivors in Beni, Butembo and Katwa health zones of the Democratic Republic of Congo. BMJ Open 2021;11:e050349. doi:10.1136/ bmjopen-2021-050349

- Prepublication history and additional supplemental material for this paper are available online. To view these files, please visit the journal online (http://dx.doi.org/10.1136/ bmjopen-2021-050349).

Received 18 February 2021 Accepted 23 July 2021

Check for updates

(C) Author(s) (or their employer(s)) 2021. Re-use permitted under CC BY-NC. No commercial re-use. See rights and permissions. Published by BMJ.

For numbered affiliations see end of article.

Correspondence to Dr Lynn Lieberman Lawry; lynn.lawry@usuhs.edu

\section{ABSTRACT}

Objectives Health and mental health characteristics of all respondents, barriers to accessing health and mental health services and the characteristics and those most at risk for mental health disorders.

Setting Beni, Butembo and Katwa health zones in the Democratic Republic of Congo.

Participants The sample contained 223 Ebola survivors, 102 sexual partners and 74 comparison respondents living in the same areas of the survivors. Survivors were eligible if aged $>18$ years with confirmed Ebola-free status. The comparison group was neither a survivor nor a partner of a survivor and did not have any household members who contracted Ebola virus disease (EVD).

Primary and secondary outcome measures Health and mental health characteristics, barriers to care and the association of association of mental health disorders with study population characteristics.

Results Funding was a barrier to accessing needed health services among all groups. Nearly one-third (28.4\%, $95 \% \mathrm{Cl} 18.0 \%$ to $38.7 \%$ ) of comparison households avoided getting injections for their children. Although most pregnant women were attending antenatal care, less than $40 \%$ of respondents stated EVD precautions were discussed at those visits. Trouble sleeping and anger were the strongest predictors of post-traumatic stress disorder, major depressive disorder (MDD), anxiety and suicide attempts with 3-fold to 16-fold increases in the odds of these disorders. There was a $71 \%$ decrease in the odds of MDD if current substance abuse (a0R $0.29 ; 95 \% \mathrm{Cl} 0.13$ to $0.67 ; p<0.01$ ) was reported.

Conclusions Specialised mental health services were limited. Fear of contracting EVD influenced vaccine compliance. Anger and sleep disorders significantly increased the odds of mental health disorders across all groups. Respondents may be using substance abuse as self-medication for MDD. Ebola outbreak areas would benefit from improved screening of mental health disorders and associated conditions like anger and sleep difficulties and improved mental health services that include substance abuse prevention and treatment.
Strengths and limitations of this study

- This randomly sampled study of adult Ebola survivors represents the entire adult survivor population in Beni, Butembo and Katwa health zones or $52 \%$ of all survivors in the 10th Ebola outbreak in the Democratic Republic of Congo.

- This cross-sectional study assesses health and mental health among Ebola survivors and their sexual partners and compares outcomes to a non-Ebola comparison group.

- The study reveals novel characteristics that increase the odds of mental health disorders among Ebola survivors and links them to known characteristics common in post-Ebola syndrome.

- The weighted findings of this study cannot be generalised to the entire population of survivors in other health zones or child survivors.

- Some outcomes of interest, when stratified by specific categories, had very small sample sizes, potentially affecting the precision of estimates.

\section{INTRODUCTION}

The Ebola virus disease (EVD) was first described in the Democratic Republic of Congo (DRC) in 1976 (then Zaire) and has occurred regularly throughout central Africa. ${ }^{1}$ The largest outbreak of EVD occurred 2104-2016 in Guinea, Sierra Leone and Liberia and caused more than 11000 deaths. ${ }^{1}$ The second largest outbreak occurred over a 22-month period (August 2018-June 2020) in the North Kivu, South Kivu and Ituri provinces in Eastern DRC. ${ }^{2}$ There were 2287 deaths reported among 3470 confirmed and probable cases, with an overall case fatality ratio of $66 \% .^{2}$ The case fatality rate $(66 \%)$, despite ring vaccination, was higher than the 
$50 \%$ case fatality rate in the West Africa epidemic. ${ }^{12}$ More than half $(57 \%)$ of those infected were women. ${ }^{2}$

North Kivu province had some of the best health indicators and preventive services of all provinces in DRC prior to the EVD outbreak. ${ }^{3-5}$ Mental health services, in part due to previous and continued international support of services addressing gender-based violence (GBV), conflict and the EVD outbreak, can be accessed at hospitals, health facilities and in the community which is provided by locally trained religious groups and lay providers. ${ }^{67}$ However, there is a paucity of psychologists and psychiatrists able to treat serious mental health disorders other than those focused on GBV survivors. ${ }^{67}$

Although it is impossible to assign Ebola as the cause of the higher rates of mental health disorders, retraumatisation that may occur from an event like an EVD outbreak can exacerbate symptoms of mental illness, become socially disabling, and contribute to the higher suicide attempt rates among survivors. ${ }^{69} 9$ In a previous study, four times as many survivors (23\%) met statistically significant symptom criteria for major depressive disorder (MDD) than partners $(6 \%)$ and post-traumatic stress disorder (PTSD) symptom criteria for survivors (24\%) and partners $(17 \%)$ was four times higher than the comparisons (6\%). [9] In addition, suicide attempts among survivors was six times higher than the comparison group. ${ }^{9}$ Substance abuse ranged from $23 \%$ among survivors and up to $51 \%$ of partners and comparison respondents. ${ }^{9}$ Data from previous studies of EVD have shown that in postconflict settings, retraumatisation and mental health problems are associated with health behaviours that hinder combatting and preventing EVD and limit access to preventive care services. ${ }^{8} 10$ To further investigate this association in the context of the eastern DRC Ebola outbreak, we conducted a cross-sectional study of EVD survivors, their sexual partners, and a comparison population in health zones (HZ) of North Kivu province with the highest numbers of EVD survivors. The specific aims of the study were to: (1) understand the health and mental health characteristics of the study sample, (2) identify barriers to accessing health and mental health services and (3) using a secondary analysis of previously reported rates of mental health disorders among the study population, define the characteristics and those most at risk for mental health disorders to make recommendations for the care of survivors and partners post-EVD. ${ }^{9}$ These data also identify opportunities to integrate EVD prevention and screening for postinfection health issues into existing health services. Given the rate of EVD infection among females $(57 \%)$, maternal, newborn, child health $(\mathrm{MNCH})$ services may be a particularly important point of integration. ${ }^{211}$

\section{METHODS}

\section{Survey sites and sample selection}

This cross-sectional survey was conducted in Beni, Butembo and Katwa HZ in DRC. Surveying of comparison households began in Beni in early February 2020 with the remaining surveys completed in Butembo and Katwa occurred between July and September 2020. The lag in survey completion was due to delays in study approvals from government officials as their focus shifted from the EVD response to the COVID-19 in 2019.

Male and female EVD survivors were eligible if aged $>18$ years and were able to present a certificate from an Ebola Treatment Centre (ETC) that confirmed Ebola-free status. Complete lists of survivors collated by the Ebola Survivor Associations contained the names and contact information for 427 eligible adult survivors (52\% of all survivors) in Beni, Butembo and Katwa HZs and were used to randomly and/or systematically select survivors for the study. ${ }^{12}$ Mabalako HZ, another area with high numbers of survivors, was excluded due to insecurity. We attempted to interview a representative number of female survivors $(\sim 57 \%)$ as they had higher infection rates than males during this outbreak. ${ }^{13}$ Comparison interviews were randomly selected within the same villages or on the same avenue as the survivor (after every third survivor interview) using a random number skip pattern from the household of the survivor (eg, the 5th house to the right). If no one was home, the data collector moved, via the same skip pattern, to the next house to the right until someone was home and could serve as a comparison. The comparison group was neither a survivor nor a partner of a survivor and did not have any household members who contracted EVD.

\section{Instruments}

We used epidemiological instruments previously developed, implemented and validated for DRC to develop a survey for survivors and their sexual partners and a similar version for the comparison group. ${ }^{61415}$ The major domains of these instruments included demographics, experiences during discharge from the ETC, EVD knowledge, stigma, condom use and risky sexual behaviours. ${ }^{9}$ Symptom assessment of mental health was measured by the Hopkins Symptom Checklist (HSCL-25) used to assess MDD (15 items) and anxiety (10 items) and by the Harvard Trauma Questionnaire (HTQ) to assess PTSD symptoms (16 items). ${ }^{16}$ Both the HSCL-25 and the HTQ have been used internationally and in conflict-affected samples. ${ }^{18-20}$ These scales were previously tested and validated in DRC. ${ }^{621}$ Questions about suicidal ideation and suicide attempts among respondents were asked and reported as yes or no responses. ${ }^{22}$

The survey was written in English and translated to Kiswahili and back translated to account for culturally sensitive wording and reviewed for content validity. Although French is the lingua franca of DRC, the areas of the survey are largely Kiswahili and Kinande speaking. The survey questions, other than EVD-related ones, had been previously pilot tested and validated among more than 2000 participants in previous studies in the same survey areas. ${ }^{61415}$ EVD-specific questions were pilot tested among eight community members in Beni. 


\section{Semi-structured interviews}

In-depth key informant interviews were used to provide additional insights into the themes and findings that emerged from the quantitative survey. Across all $3 \mathrm{HZ}$, 8 EVD survivors, partners and community members, 6 community leaders and 15 healthcare providers and nongovernmental organisation (NGO) staff were interviewed. Convenience, purposeful and snowball sampling (nonprobability sampling) methods were used to allow flexibility in accessing individuals who might be important for informing the quantitative data. Interviews were conducted in French, Kiswahili or Kinande, and notes were taken during the interview on a computer to allow for simultaneous transcription, being careful to write exactly how issues and concerns were expressed by the respondent. The topics discussed included awareness of the causes of EVD, concerns since discharge or concerns about survivors in the community after discharge, postrecovery services offered, changes in sexual behaviour and stigma. Respondents were also given the opportunity to discuss other issues. Additionally, a subset of short qualitative responses was obtained from the quantitative survey $(n=399)$.

\section{Interviewers}

Four locally hired and EVD vaccinated data collectors were trained by one expatriate researcher and one Congolese supervisor over 3 days to conduct one-on-one interviews. Training included a combination of classroom teaching, experimental role-play and field testing. Data collectors learnt to verbally administer the survey in Kiswahili and Kinande. The verbal translations from Kiswahili into Kinande were checked for accuracy by members of the research team. Interviews were conducted anonymously in a setting that offered privacy and confidentiality, typically inside the housing unit if masks were available and social distancing could be maintained. If not, interviews were completed outside away from others to preserve confidentiality and ensure social distancing. Oral rather than written consent was obtained because of the high illiteracy rate and the need for confidentiality. Participants did not receive any material compensation. They were informed that participation or lack thereof would not affect their access to or the quality of the care they receive and were explicitly given the right to refuse participation. Password-protected tablets were used with the Kiswahili translation of the survey for data to limit data loss and to allow for remote monitoring. The data collectors were supervised throughout the survey period, and data was uploaded at the end of the day and reviewed by the study team nightly.

\section{Data analysis}

\section{Quantitative analysis}

Sample size was determined by the known prevalence of major depression of $0.4{ }^{6}$ The sample size required to estimate that prevalence via a simple random sample, to within 0.05 with $95 \%$ confidence, was 199 survivors. The study targeted 225 EVD survivors (of the 427) in the 3 HZs to account for refusals and to ensure representativeness of the sample. A subset of sexual partners of the randomised survivors were also surveyed. The original target sample size for partners was 225. Only $45 \%$ $(110 / 225)$ of those were interviewed, due to partners being away from households for work, not wanting to participate in a lengthy interview, and/or not wanting to talk about their experiences due to stigma. XLSTAT and STATA 16 were used to perform the statistical analyses. Analysis involved the estimation of weighted population and subpopulation means and percentages. As previously described, $58 \%$ of the survivor sample was female and $42 \%$, male. ${ }^{9}$ The mean age (range $33-38$ years) was not statistically different across respondent groups. ${ }^{9}$ The majority reported to be married, Christian, Nande ethnic group, farmers/herders and Kiswahili speakers. ${ }^{9}$ An average HSCL-25 score of 1.75 or higher and an average HTQ score of 1.75 or higher was considered predictive of clinically significant depression or anxiety and PTSD, respectively, based on data from other conflict-affected populations. ${ }^{19} 2324$ Data were weighted to account for population differences of the HZ and numbers of survivors. ${ }^{9}$ Multivariate logistic regression models were used to investigate the association of mental health disorders with study population characteristics. Variables found to be significant in bivariate analysis were included as cofounders in the multivariate model. Because missing data were minimal for relevant variables $(<5 \%)$, observations with missing data were dropped from analyses.

\section{Qualitative analysis}

Qualitative data were translated into English. In-depth narratives from the key informant interviews and qualitative data from the quantitative surveys were summarised and compiled into a master Excel spreadsheet by outcomes and questions on the instruments. Qualitative data were collected to complement and triangulate the quantitative data. All data were analysed using content analysis (specifically conceptual content analysis). ${ }^{25}$ Themes, developed collaboratively with local field staff to ensure culturally and contextually appropriate interpretation of the analysis, were hand-coded, analysed, categorised by the first author and reviewed by additional authors for concurrence.

\section{Patient and public involvement}

The Ebola Survivor Associations of Beni, Butembo and Katwa were involved in recruiting participants and in dissemination of the results.

\section{RESULTS}

\section{Health services accessed}

The most accessed health services by all respondents included pharmacies, health centres and hospitals (table 1). The most stated barrier to accessing needed health services among survivors $(57 \%)$, partners $(70 \%)$ and the comparison group (49\%) was the lack of money to pay for such 
Table 1 Health services accessed

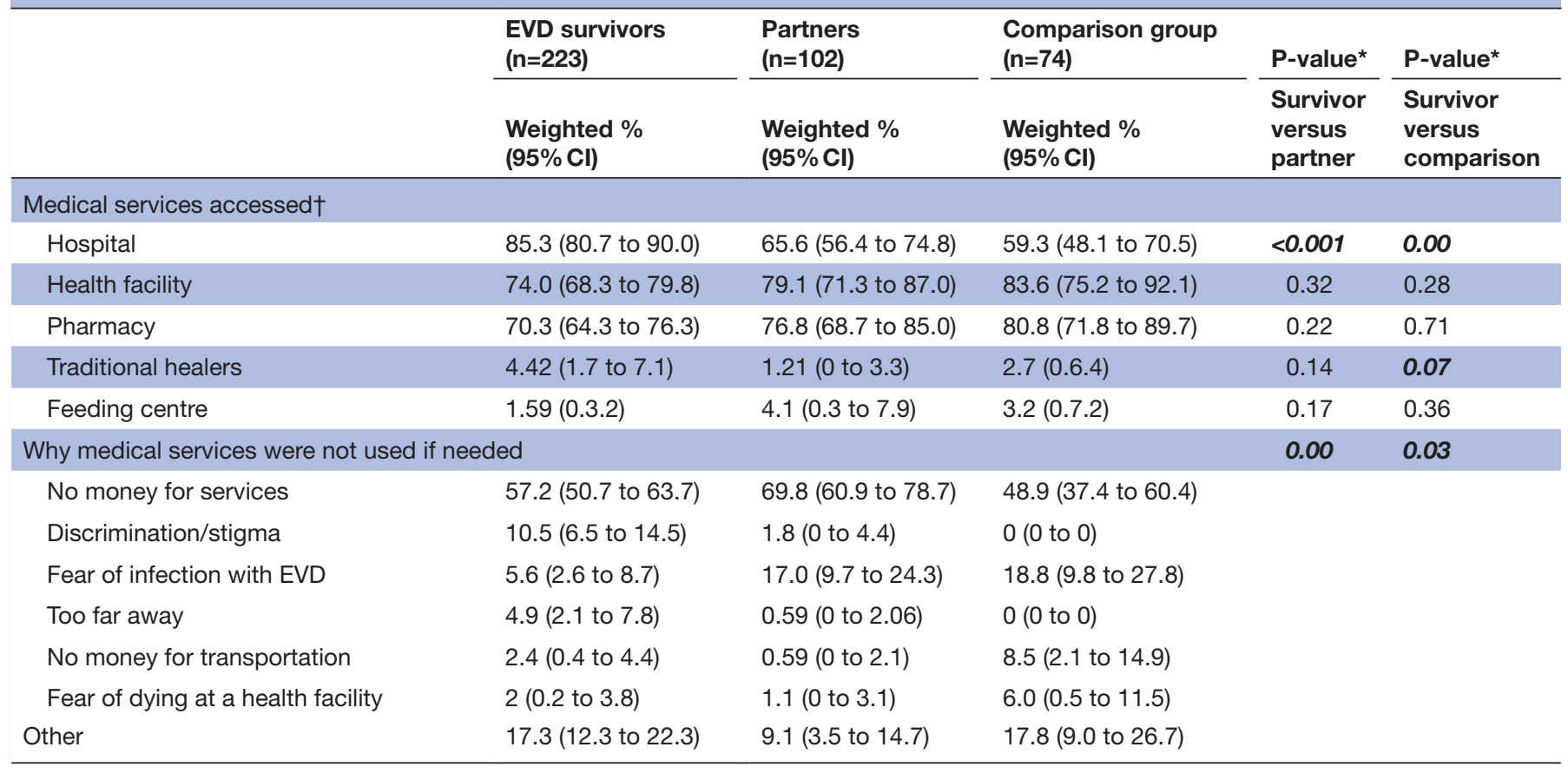

Bold/italicized P-values denote statistical significance

${ }^{*}$ Pearson $x^{2}$ test.

†Other: survivors and partners: nothing $n=38$, prefer traditional medicine $n=2$, no time $n=2$, spouse refused $n=1$, lack of quality care/distrust $n=4$; comparison: nothing $n=12$, fear of health facility $n=4$.

EVD, Ebola virus disease.

services $(\mathrm{p}<0.05)$. Stigma was not a commonly stated barrier to care. However, $10 \%$ of survivors did report stigma as a reason for not accessing services if they were needed. Among partners (17\%) and the comparison group (19\%), fear of EVD infection was the second commonly stated barrier to accessing healthcare services.

\section{Maternal and child healthcare access and characteristics}

During the EVD epidemic, nearly a third $(28.3 \%, 95 \%$ CI $18.0 \%$ to $38.7 \% ; \mathrm{p}<0.001)$ of comparison households stated they avoided getting injections for their children compared with $4.5 \%$ (95\% CI $1.8 \%$ to $7.2 \%$ ) of survivors and $9.4 \%$ (95\% CI $3.7 \%$ to $15.1 \%$ ) of partners (table 2). Of those pregnant at the time of the study $(n=34)$, planned pregnancies were more than twice as common among survivors $(83.6 \%, 95 \%$ CI $66.5 \%$ to $100 \%)$ and partners $(72.8 \%$, $95 \%$ CI $48.6 \%$ to $96.9 \%$; $\mathrm{p}=0.05$ ), than comparison women (36.2\%; 95\% CI $0 \%$ to $83.9 \%$ ). Forty per cent of pregnancies among the comparison group were due to violence. Less than half of survivors $(47.9 \%, 95 \%$ CI $24.9 \%$ to $71.0 \%)$ stated they planned to breastfeed. Although most pregnant individuals surveyed were attending antenatal care visits (ANC), only $7 \%$ survivors, $19 \%$ of partners and $39 \%$ of community comparisons reported that EVD precautions were discussed at those visits.

\section{Mental healthcare access}

Clinics and hospitals across the three HZs were reported to have mental health services (table 3). Respondents in Beni stated that religious groups and traditional healers were involved in mental healthcare. Among respondents, up to $21 \%$ did not know if services were available in their HZ. Post-Ebola psychosocial support was reported as available in each HZ.

Most of the survivors $87.0 \%$ (95\% CI $82.6 \%$ to $91.4 \%$ ) and one-third of partners $(33.5 \%, 95 \% \mathrm{CI} 24.3 \%$ to $42.6 \%)$ had received mental health counselling since August 2018 compared with $16 \%$ of the comparison group (online supplemental table 1). More than $50 \%$ of all respondents stated there was 'nothing' that would stop them accessing mental health services, although $13.2 \%$ (95\% CI $6.7 \%$ to $19.8 \%$ ) of partners stated that shame would stop them and $25.6 \%$ (95\% CI $15.6 \%$ to $35.5 \%$ ) of comparison respondents stated they believed services were not necessary. Religion, discussions with friends and family support were reported as the most helpful means for dealing with their experiences during EVD across all three groups. One-third of survivors $(31.9 \%, 95 \%$ CI $25.8 \%$ to $38.0 \%$ ) stated 'trying to forget about it' was helpful while employment was more frequently stated by partners and comparisons.

\section{Mental health characteristics}

More than half of survivors and partners self-reported anger compared with one-third of the comparison group (table 4). More than half of all respondents also reported sleep difficulties. More comparison households $(5.4 \%$, $95 \% \mathrm{CI} 0.2 \%$ to $10.5 \%)$ and partners $(4.7 \%, 95 \% \mathrm{CI}$ $0.6 \%$ to $8.9 \%$; $\mathrm{p}=0.05$ ) reported a household member 
Table 2 Maternal child health access and characteristics

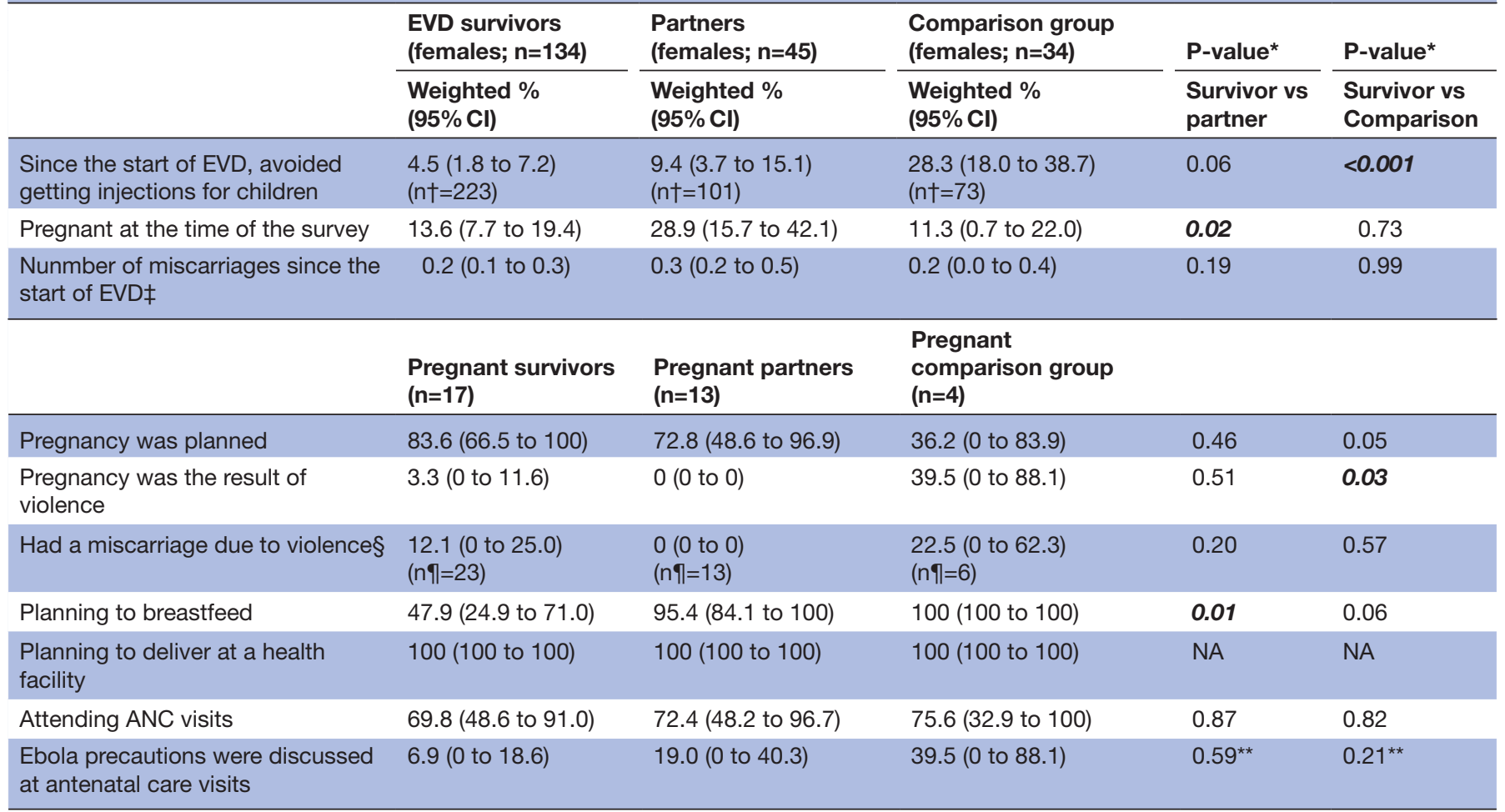

${ }^{*}$ Categorical variables: Pearson $x^{2}$ test; continuous variables: two tailed t-test, prior use of an F-test to determine whether variance can be assumed to be equal.

$\mathrm{tn}=$ all participants and therefore includes men and women.

$\ddagger$ Continuous variable.

$\S n=a m o n g$ all women reporting a miscarriage; limits to $p$ values due to small sample size and Cls.

ๆn=the number of women who reported at least one miscarriage since August 2018.

** Limitations to $p$ values due to small sample size and Cls.

ANC, antenatal care; EVD, Ebola virus disease; NA, not available.

committed suicide when compared with survivor households $(1.1 \%, 95 \%$ CI $0 \%$ to $2.5 \%$; $\mathrm{p}=0.03)$. Fear of EVD $(88 \%-98 \%)$ and fear of sexual violence by combatants $(73 \%-83 \%$ among all respondents) was high. Most households feared EVD as much as they feared sexual violence by combatants and feared sexual violence by combatants approximately eight times more than sexual violence by others. Substance use largely decreased

Table 3 Mental health services reportedly available by health zone $(\mathrm{HZ})$

\begin{tabular}{|c|c|c|c|c|}
\hline & Beni $(n=145)$ & Butembo $(n=128)$ & Katwa $(n=126)$ & P-value* \\
\hline & $\%(95 \% \mathrm{Cl})$ & $\%(95 \% \mathrm{Cl})$ & $\%(95 \% \mathrm{Cl})$ & By HZ \\
\hline \multicolumn{5}{|l|}{ Mental health services available } \\
\hline Hospital & 44.8 (36.7 to 52.9$)$ & $43.0(34.4$ to 51.5$)$ & 51.6 (42.9 to 60.3 ) & 0.35 \\
\hline Clinic & 17.2 (11.1 to 23.4$)$ & 42.2 (33.6 to 50.7$)$ & 16.7 (10.2 to 23.2$)$ & $<0.001$ \\
\hline I don't know & $11.7(6.5$ to 17.0$)$ & 21.1 (14.0 to 28.2 ) & 17.5 (10.8 to 24.1$)$ & 0.11 \\
\hline Ebola/post-Ebola psychosocial support & $10.3(5.4$ to 15.3$)$ & 24.2 (16.8 to 31.6$)$ & 19.0 (12.2 to 25.9$)$ & 0.01 \\
\hline One-on-one counselling & 2.07 (0 to 4.4$)$ & $8.6(3.7$ to 13.4$)$ & 7.9 (3.2 to 12.7$)$ & 0.04 \\
\hline Rehabilitation centres & $0.7(0$ to 2.0$)$ & $2.3(0$ to 5.0$)$ & $2.4(0$ to 5.0$)$ & 0.47 \\
\hline
\end{tabular}

*Pearson $x^{2}$ test applied to compare reported service availability by $\mathrm{HZ}$. 
Table 4 Mental health characteristics

\begin{tabular}{|c|c|c|c|c|c|}
\hline & EVD survivors $(n=223)$ & $\begin{array}{l}\text { Partners } \\
(n=102)\end{array}$ & $\begin{array}{l}\text { Comparison group } \\
(n=74)\end{array}$ & P-value* & P-value* \\
\hline & $\begin{array}{l}\text { Weighted \% } \\
(95 \% \mathrm{Cl})\end{array}$ & $\begin{array}{l}\text { Weighted \% } \\
(95 \% \mathrm{Cl})\end{array}$ & $\begin{array}{l}\text { Weighted \% } \\
(95 \% \mathrm{Cl})\end{array}$ & $\begin{array}{l}\text { Survivor vs } \\
\text { partner }\end{array}$ & $\begin{array}{l}\text { Survivor vs } \\
\text { comparison }\end{array}$ \\
\hline $\begin{array}{l}\text { Feeling irritable or having } \\
\text { outbursts of anger }\end{array}$ & 60.9 (54.5 to 67.3$)$ & 56.0 (46.4 to 65.7 & 26.2 (16.2 to 36.2 ) & 0.40 & $<0.001$ \\
\hline Trouble sleeping & $57.6(51.1$ to 64.1$)$ & 55.7 (46.0 to 65.3$)$ & 52.1 (40.7 to 63.5$)$ & 0.75 & 0.41 \\
\hline $\begin{array}{l}\text { Sexual violence by } \\
\text { combatants is something } \\
\text { feared for self and family }\end{array}$ & $\begin{array}{l}83.1(78.2 \text { to } 88.2) \\
(n=218)\end{array}$ & $\begin{array}{l}72.6(63.9 \text { to } 81.4) \\
(n=100)\end{array}$ & $\begin{array}{l}82.5(73.7 \text { to } 91.2) \\
(n=74)\end{array}$ & 0.01 & 0.82 \\
\hline $\begin{array}{l}\text { Sexual violence by family } \\
\text { members, friends, or civilian } \\
\text { strangers is something feared } \\
\text { for self and family }\end{array}$ & $\begin{array}{l}18.5(13.4 \text { to } 23.7) \\
(n=219)\end{array}$ & $\begin{array}{l}8.2(2.8 \text { to } 13.6) \\
(n=100)\end{array}$ & $\begin{array}{l}4.0(0.0 \text { to } 8.5) \\
(n=74)\end{array}$ & 0.02 & 0.00 \\
\hline \multicolumn{6}{|c|}{ Change in substance use since August 2018} \\
\hline Increased & 3.4 (1.0 to 5.7$)$ & 8.0 (2.7 to 13.3$)$ & 9.3 (2.6 to 16.0$)$ & $<0.001$ & $<0.001$ \\
\hline Decreased & 35.3 (29.0 to 41.5$)$ & 16.0 (8.9 to 23.2$)$ & 9.1 (2.4 to 15.7$)$ & & \\
\hline Remained the same & $6.8(3.5$ to 10.1$)$ & 35.3 (25.9 to 44.6$)$ & 23.5 (13.8 to 33.3$)$ & & \\
\hline Never used & 54.0 (47.5 to 60.5$)$ & 40.7 (32.1 to 50.3$)$ & 55.3 (43.9 to 66.8$)$ & & \\
\hline
\end{tabular}

*Pearson $x^{2}$ test.

EVD, Ebola virus disease.

among survivors since the start of the outbreak. Comparison respondents had the highest rate of increase in substance use since the start of outbreak.

Respondent group, sex, education, employment status and reported stigmatisation had no statistically significant associations with MDD, PTSD, anxiety or lifetime suicide attempts (table 5). Trouble sleeping and anger were the strongest predictors of PTSD, MDD, anxiety and suicide attempts. For those with PTSD, after adjusting for confounders, the odds were 16-fold higher (aOR 17.8, 95\% CI 6.1 to $52.1 ; \mathrm{p}<0.001)$ for those who reported trouble sleeping and 15-fold higher (aOR 16.1, 95\% CI 4.5 to $47.3 ; \mathrm{p}<0.001)$ if they reported anger.

For those who made symptom criteria for MDD, there was a $2 \%$ increase in the odds of MDD for every 1-year increase in age $(\mathrm{p}<0.05)$, an $88 \%$ decrease in the odds of MDD if you were a partner of a survivor $(p<0.01)$, a $49 \%$ decrease if married $(\mathrm{p}<0.05)$ and a $71 \%$ decrease if substance abuse was self-reported $(\mathrm{p}<0.01)$. Like PTSD, with self-reported trouble sleeping (aOR 3.89, 95\% CI 1.9 to $8.1 ; \mathrm{p}<0.001$ ) and anger (aOR $6.2,95 \%$ CI 2.7 to 13.8 ; $\mathrm{p}<0.001)$ there was a threefold to fivefold increase in the odds of MDD.

Trouble sleeping increased the odds of anxiety sixfold and (aOR 6.73, 95\% CI 2.5 to 18.0) and lifetime suicide attempts three-fold (aOR $3.53,95 \%$ CI 1.4 to 8.8 ). The odds of anxiety were 12 fold higher if respondents reported anger (aOR 12.57, 95\% CI 3.7 to 43.1 ) and associated with a threefold increase in lifetime suicide attempts (aOR $3.76,95 \% \mathrm{CI} 1.5$ to 9.4 ).

\section{Qualitative findings}

In-depth interviews revealed that healthcare access for preventive care had suffered during the EVD emergency. Community health workers (CHWs) were paid US\$300US $\$ 350$ during the epidemic for EVD case referrals and for community messaging. Participants were asked if they would return to their normal volunteer roles in the community, given their CHW positions became paid as part of the emergency response. The US $\$ 300$ per month stipend given to CHWs is half of an average yearly salary of most Congolese households. ${ }^{26}$ It is likely that volunteers who were paid for the emergency response will put the health prevention and promotion role of volunteer CHWs at risk and potentially decrease available preventative services especially for women and children:

When I see other people [communicators and people working in offices] being paid why should we not be paid? When the response teams came, they were giving money to everyone; we realized that Ebola was all about money (Male Community Health Worker-Beni)

If they stop paying me to do sensitization, I will just go back to farming...everyone knows Ebola is money (Female Community Health Worker-Beni) 


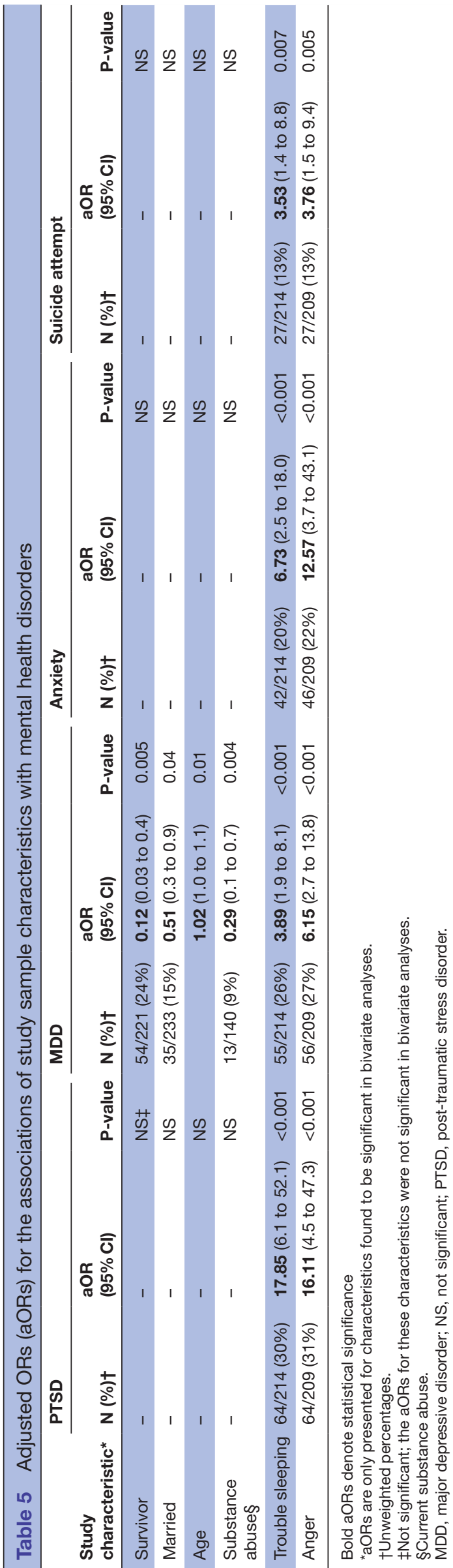

Interviews also revealed that healthcare providers and NGO personnel had frustration with the 'all-consuming nature of the response', leaving programming gaps, such as childhood vaccines, malaria and diarrhoea prevention campaigns. They expressed worry about the long-term effects of the gaps in coverage over the 22 months of the epidemic response. One HZ chief doctor stated he spent all his time on Ebola, leaving little to no time to address health issues like tuberculosis, MNCH or vaccinations. He stated that 'Ebola broke the system' when referring to the decision to pay CHWs and other volunteers who were the 'backbone of the preventive healthcare system'.

Short answer qualitative findings and in-depth interviews revealed that refusing injections (vaccines) for children was driven by a fear of infection, fear of contracting EVD at a health facility and/or the belief that EVD was being purposely injected at health facilities. As one participant stated, 'I hear they are infecting people with the virus, so I am afraid'. (Male Comparison Respondent)

In-depth interviews added important context to the mental health data. During key informant interviews, many of the survivors and partners interviewed appeared angry. When asked about the anger, it stemmed from home life issues, including the lack of employment, loss of a child, financial deprivation after infection, taking in orphans with no support and ongoing stigma and discrimination. One respondent, when asked why she was angry stated the following:

I am very angry, and because I lost a child [to Ebola] and then I got Ebola... many people talk about Ebola but they don't know what it really is. They don't understand my pain and I feel stigmatized. (Female Survivor-Butembo)

Compounding the anger was the reality that more than half of the survivors and partners that reported having to move households after contracting Ebola, also had to leave their communities because of violence. A female survivor stated:

One of my neighbours died of Ebola and then they said that if I was healed why did I give her Ebola so they attacked my house and demolished it by burning it with all my things. (Female Nurse Survivor-Beni)

\section{DISCUSSION \\ Healthcare access}

Two decades of continuous violent civil conflicts and insecurity in North Kivu have created significant government health system weaknesses, particularly at the HZ level where planning of healthcare services is implemented . 3572728 Thus, North Kivu is one of two provinces with the highest percentage of for-profit and humanitarian assistance run health services. ${ }^{3}$ Given these challenges, EVD survivors are monetarily incentivised by third party providers such as WHO and the Ministry of Health for monthly post-EVD care. This care includes medical care, 
psychological counselling for survivors and partners, and medical follow-up of children under 15 years of survivor families and is expected to continue through March 2022. ${ }^{29}$ Since access to medical care and psychological services for survivors are monetarily incentivised and provided cost-free, it is not clear why over half of survivors state they were unable to access services due to lack of funding. Health financing is dependent on household out-of-pocket payments, so it may be that the financial barrier applies to care for other family members. ${ }^{2}$ In a previous study more than one-quarter of survivors stated they were stigmatised by facilities and/or healthcare staff, their expressed fear regarding stigmatisation in health facilities $(10 \%)$ was worse in practice. ${ }^{9}$

\section{Maternal and child healthcare access and characteristics}

Vaccines remain one of the most efficient and costeffective public health interventions to reduce child mortality. ${ }^{30}$ Vaccination rates in DRC improved between 2007 and 2014 and North Kivu had the highest prevalence of full vaccination $(66 \%) .{ }^{31}$ However, that still means that $44 \%$ of infants and children did not have full vaccination. ${ }^{31}$ During the EVD outbreak, vaccination rates for early childhood diseases began declining in 2019, with decreases of $10 \%$ reported. $^{32}{ }^{33}$ With these decreasing rates now compounded by COVID-19, vaccine hesitancy, based on fears and misinformation, could have a further deleterious effect on infants and children. ${ }^{32} 34$

Mortality rates among women and children in DRC have decreased over the last decade but remain high. Contributions to the high maternal mortality rate include preventable diseases, inadequate prenatal and postnatal care, unequal power dynamics and decision making between women and men, and harmful practices such as early marriage. ${ }^{63031}$ These factors contribute to the high GBV rate in the areas and may explain the high number of unplanned pregnancies and miscarriages due to violence among the comparison group. ${ }^{631}$ Higher rates of planned pregnancy among survivors and partners is likely due to the requirement to have viral clearance before planning or getting pregnant as per their monthly follow-up. Focused ANC is essential to decrease newborn mortality. ${ }^{35}$ During the EVD outbreak and in this sample, between a quarter and one-third of pregnant women were not attending ANC visits which is similar to decreases in ANC visits in the West Africa EVD outbreak. ${ }^{34}{ }^{36}$ Among those who attended ANC, the lack of EVD precautions discussed at these visits suggests patients are not receiving important, and potentially life-saving, information about infection prevention control measures, condom use, and means to combat myths and misinformation. Providing accessible information on these topics is important for addressing barriers to maternal and child healthcare seeking and utilisation especially for EVD survivors and partners. ${ }^{36}$ Despite lessons learnt from the West Africa EVD outbreak, some of the same mistakes such as decreased access to and utilisation of ANC and other important services for endemic diseases like malaria, ${ }^{34}$ and failing to prevent excess deaths among pregnant, non-EVD infected individuals, were repeated in DRC. ${ }^{36-38}$ Integrating EVD awareness into maternal and child health services at the outset, in addition to community messaging, is prudent to decrease mortality and morbidity for women and children resulting from lack of preventive care. ${ }^{34} 3940$

Exclusive and immediate breast feeding is known to prevent $38 \%$ of neonatal deaths. ${ }^{31}{ }^{40}$ Despite a lack of evidence that breast milk can transmit EVD from mother to child, DRC recommendations state that EVD survivors with cleared viraemia should wait for two consecutive negative tests to resume breast feeding. ${ }^{41-43}$ Thus, nearly half of the pregnant survivors are planning to breastfeed even with guidelines that suggest they should not. And without evidence-based research on EVD and breastmilk, discouraging breast feeding can have significant effects on infant mortality and morbidity and setback public health efforts and gains in promoting breast feeding especially within the DRC context. ${ }^{43}$

\section{Mental healthcare access}

Those living in outbreak areas had poor mental health at baseline, partly due to these areas being postconflict and chronically insecure with a high prevalence of sexual violence. ${ }^{644}$ There is a lack of specialised mental health services in North Kivu, and community members have little choice in service and treatment options. ${ }^{7}$ Mental healthcare is largely provided by lay personnel such as religious leaders or trusted community members using active listening, feedback or in special circumstances cognitive processing therapy (CPT) for sexual violence survivor programmes. ${ }^{2144} 45$ Survivors and partners are offered limited psychological evaluations and care during their monthly follow-up appointments. ${ }^{45}$ The availability and quality of treatment for more severe mental health disorders such as suicidal ideation, suicide attempts and PTSD in Ebola affected HZs remains unclear.

\section{Mental health characteristics}

Anger and sleep quality index scales have not, to the authors' knowledge, been used in DRC and would require adaption and validation. ${ }^{46}$ Anger among the study population was significantly associated with PTSD, MDD, anxiety and suicide attempts. Mental health screening should include anger scales, given their association with these and other mental health disorders. ${ }^{4} 49$

Furthermore, collective community anger should be addressed in the EVD outbreak areas given the chronic conflict, rates of GBV and associated mental health disorders. ${ }^{6}$ Addressing anger broadly among entire communities will serve to help everyone, not just survivors and partners, and may help to prevent further traumatisation and the severity of mental health disorders in future outbreaks of EVD..$^{50}$

Across Africa, sleep disorders are theorised to be caused by genetic predisposition, testosterone and oestrogen decline, inflammation, obesity, environmental factors and are common among HIV-positive patients and 
in areas where African Trypanosomiasis is endemic. ${ }^{52} 53$ And although sleep disorders among EVD survivors is a common complaint of the post-Ebola syndrome, the cause of the reported sleep disorders remains unknown. ${ }^{5455} \mathrm{It}$ is possible the erectile dysfunction and menstrual changes commonly seen among survivors post-Ebola are hormone related which contribute to the sleep disorders. ${ }^{54-56}$ Given the strong association of sleep difficulties with mental health disorders in this study, sleep quality scales should be administered to identify those at risk for mental health disorders. ${ }^{465657}$ Additionally, further research to better define the causes of the sleep disorders may help to identify, treat, and alleviate the burden and severity of mental health disorders. The protective effects of substance use/abuse for MDD suggests that alcohol and or drugs are being used to self-medicate (SM), a well-established phenomenon among those with MDD and anxiety. ${ }^{58} 59$ Screening for and addressing substance abuse and SM behaviours should be concurrent with the treatment of MDD and anxiety in this population. ${ }^{589}$

It is also possible that the effects of fear and death around survivors and their families is exacerbating symptoms of mental health disorders stemming from trauma from GBV and conflict/insecurity in outbreak areas. Exacerbation of symptoms can become socially disabling and may be a reason for the higher suicide attempt rates among household members. ${ }^{910}$

With a dearth of specialised psychiatric practitioners in DRC, some of the already trained lay providers could be helpful in screening and treatment of survivors, partners and the community for specific mental health disorders, like PTSD, MDD and anxiety. By using CPT or psychological first aid, they may be able to address symptoms such as anger which increase the odds of significant mental health disorders and treat the substance abuse concurrently. ${ }^{721} 4448-5160$

\section{LIMITATIONS}

The weighted findings of this study represent the adult survivor populations in Beni, Butembo and Katwa HZs and cannot be generalised to the entire population of survivors in other HZs or child survivors. The sample weights are based on population estimates from the DRC, District Health Information Service 2.0, and therefore, may introduce bias given there is no census data to rely on. Some outcomes of interest, when stratified by specific categories, had very small sample sizes, potentially affecting the precision of estimates. The design of this study allows for the determination of population characteristics but not causality between those characteristics and outcomes of interest. Interviewers were careful to explain there would be no material gain by participation in the study; however, respondents may have underestimated or exaggerated responses if they thought it would be in their interest to do so. The mental health instruments used to determine the prevalence of symptom criteria for mental health disorders do not substitute for clinician diagnosis.

\section{CONCLUSION}

This study suggests the inability to pay for services, fear of being stigmatised or contracting EVD had a role in limiting access for all health services. Sustainable, affordable and accessible healthcare, including specialised mental healthcare, in North Kivu must continue to be prioritised by both the government and donors. EVD awareness should be integrated into preventive care such as MNCH care. The community would benefit from improved screening of mental health disorders including anger and sleep difficulties and improved mental health services should integrate substance abuse into treatment. Community based trauma healing may improve community health after EVD and perhaps prevent further trauma induced exacerbation of mental health disorders and address the anger in communities. Lay counsellors, trained in CPT for GBV survivors, could be an effective and efficient means of screening and addressing a range of mental health issues in EVD outbreak areas to fill the void of specialised services necessary for EVD outbreak area populations. Further research using clinical reasoning that deciphers and ties post-Ebola syndrome symptoms to clinical outcomes is necessary to better meet the medical needs for survivors and outbreak area communities at large.

\section{Author affiliations}

${ }^{1}$ Preventive Medicine and Biostatistics, Uniformed Services University of the Health Sciences F Edward Hébert School of Medicine, Bethesda, Maryland, USA

${ }^{2}$ IMA World Health, Washington, DC, USA

${ }^{3}$ Consulting Statistician, Perales de Tajuña, Spain

${ }^{4}$ IMA World Health, Goma, Congo

Contributors LLL, NSK and CC had full access to the data in the study and take responsibility for the integrity of the data and the accuracy of the data analysis. Study concept and design: LLL, NSK and WC. Acquisition of data: LLL. Analysis and interpretation of data: LLL and NSK. Drafting of the manuscript: LLL. Critical revision of the manuscript for important intellectual content: LLL, NSK, WC and CC. Statistical analysis: CC, LLL and NSK. Obtained funding: NSK and WC. Administrative, technical or material support: NSK, LLL and WC. Study supervision: LLL.

Funding This study was made possible by the generous funding of IMA World Health and its contributing donors. Award/grant number-N/A.

Competing interests None declared.

Patient consent for publication Not required.

Provenance and peer review Not commissioned; externally peer reviewed.

Data availability statement Data are not publically available. However, requests for data can be made in writing to IMA World Health.

Supplemental material This content has been supplied by the author(s). It has not been vetted by BMJ Publishing Group Limited (BMJ) and may not have been peer-reviewed. Any opinions or recommendations discussed are solely those of the author(s) and are not endorsed by BMJ. BMJ disclaims all liability and responsibility arising from any reliance placed on the content. Where the content includes any translated material, BMJ does not warrant the accuracy and reliability of the translations (including but not limited to local regulations, clinical guidelines, terminology, drug names and drug dosages), and is not responsible for any error and/or omissions arising from translation and adaptation or otherwise.

Open access This is an open access article distributed in accordance with the Creative Commons Attribution Non Commercial (CC BY-NC 4.0) license, which permits others to distribute, remix, adapt, build upon this work non-commercially, and license their derivative works on different terms, provided the original work is 
properly cited, appropriate credit is given, any changes made indicated, and the use is non-commercial. See: http://creativecommons.org/licenses/by-nc/4.0/.

ORCID iD

Lynn Lieberman Lawry http://orcid.org/0000-0001-8229-8768

\section{REFERENCES}

1 World Health Organization. Ebola virus disease. Available: https:// www.who.int/news-room/fact-sheets/detail/ebola-virus-disease [Accessed 18 Aug 2020].

2 World Health Organization. Ebola virus disease - Democratic Republic of Congo. Available: https://www.who.int/csr/don/26-June2020-ebola-drc/en/ [Accessed 17 Aug 2020].

3 Demographic and Health Survey. République Démocratique du Congo, Évaluation des Prestations des services de soins de Santé (EPSS) 2017-2018. Available: https://dhsprogram.com/pubs/pdf/ SPA30/SPA30.pdf [Accessed 12 Jan 2021].

4 Demographic and Health Survey (DRC-DHS II). Supplemental malaria report. 2013-1014. Available: https://dhsprogram.com/pubs/pdf/ FR300/FR300.Mal.pdf [Accessed 12 Jan 2021].

5 Altare C, Malembaka EB, Tosha M, et al. Health services for women, children and adolescents in conflict affected settings: experience from North and South Kivu, Democratic Republic of Congo. Confl Health 2020;14:31.

6 Johnson K, Scott J, Rughita B, et al. Association of sexual violence and human rights violations with physical and mental health in territories of the eastern Democratic Republic of the Congo. JAMA 2010;304:553-62.

7 Social Science in Humanitarian Platform. Key considerations: mental health and psychosocial support, North Kivu, DRC, 2018. Available: https://opendocs.ids.ac.uk/opendocs/bitstream/handle/20.500. 12413/14088/MHPSS_key_considerations_Ebola_North_Kivu_DRC. pdf?sequence=1\&isAllowed $=y$ [Accessed 12 Jan 2021].

8 O'Leary A, Jalloh MF, Neria Y. Fear and culture: contextualising mental health impact of the 2014-2016 Ebola epidemic in West Africa. BMJ Glob Health 2018;3:e000924.

9 Lawry L, Stroupe-Kannappan N, Canteli C. Assessment of mental health and sexual behaviours among Ebola survivors in North Kivu, Democratic Republic of Congo. BMJ Open 2021.

10 Betancourt TS, Brennan RT, Vinck P, et al. Associations between mental health and Ebola-related health behaviors: a regionally representative cross-sectional survey in post-conflict Sierra Leone. PLoS Med 2016;13:e1002073.

11 Quaglio G, Tognon F, Finos L, et al. Impact of Ebola outbreak on reproductive health services in a rural district of Sierra Leone: a prospective observational study. BMJ Open 2019;9:e029093.

12 United Nations Child Fund. Ebola survivors serving their communities. Available: https://www.unicef.org/drcongo/en/stories/ ebola-survivors-serving-their-community [Accessed 18 Aug 2020].

13 United Nations Population Fund. New Ebola outbreak hits women and girls hardest in the Democratic Republic of the Congo. Available: https://www.unfpa.org/news/new-ebola-outbreak-hits-women-andgirls-hardest-democratic-republic-congo [Accessed 18 Aug 2020].

14 Lawry L. A population-based household study to assess practical strategies of prevention and response to sexual and gender based violence in Katana, Walikale, and Karisimbi health zones, DRC, 2016. https://imaworldhealth.org/wp-content/uploads/2016/11/OSC-IMAUshindi-Baseline-2016-.pdf

15 Lawry L. Overcoming sexual and gender-based violence in Eastern Democratic Republic of Congo. Available: https://imaworldhealth. org/wp-content/uploads/2016/12/OSC-IMA-Ushindi-ImpactEvaluation-Final.pdf [Accessed 18 Aug 2020].

16 Veijola J, Jokelainen J, Läksy K, et al. The Hopkins symptom Checklist-25 in screening DSM-III-R axis-I disorders. Nord $J$ Psychiatry 2003;57:119-23.

17 Harvard trauma questionnaire (HTQ. Available: http://hprt-cambridge. org/screening/harvard-trauma-questionnaire/ [Accessed 18 Aug 2020].

18 Tsutsumi A, Izutsu T, Poudyal AK, et al. Mental health of female survivors of human trafficking in Nepal. Soc Sci Med 2008;66:1841-7.

19 Mollica RF, Caspi-Yavin Y, Bollini P, et al. The Harvard trauma questionnaire. validating a cross-cultural instrument for measuring torture, trauma, and posttraumatic stress disorder in Indochinese refugees. J Nerv Ment Dis 1992;180:111-6.

20 Ventevogel P, De Vries G, Scholte WF, et al. Properties of the Hopkins symptom Checklist-25 (HSCL-25) and the self-reporting questionnaire (SRQ-20) as screening instruments used in primary care in Afghanistan. Soc Psychiatry Psychiatr Epidemiol 2007;42:328-35.

21 Bass JK, Annan J, Mclvor Murray S, et al. Controlled trial of psychotherapy for Congolese survivors of sexual violence. $N$ Engl J Med 2013;368:2182-91.

22 National Institutes of Health. Suicide and suicidal behavior. Available: http://www.nlm.nih.gov/medlineplus/ency/article/001554.htm\# Definition [Accessed 29 Jan 2021].

23 Mollica RF, Wyshak G, de Marneffe D, et al. Indochinese versions of the Hopkins symptom Checklist-25: a screening instrument for the psychiatric care of refugees. Am J Psychiatry 1987;144:497-500.

24 McDonald SD, Calhoun PS. The diagnostic accuracy of the PTSD checklist: a critical review. Clin Psychol Rev 2010;30:976-87.

25 Hsieh H-F, Shannon SE. Three approaches to qualitative content analysis. Qual Health Res 2005;15:1277-88.

26 World Bank. Gross domestic product per capita: Democratic Republic of Congo, 2019. Available: https://data.worldbank.org/ indicator/NY.GDP.PCAP.CD?locations=CD [Accessed 31 Jan 2021]

27 World Health Organization. Health services accessed Democratic Republic of Congo: improving aid coordination in the health sector, 2015. Available: https://apps.who.int/iris/bitstream/handle/10665/ 186673/WHO_HIS_HGF_CaseStudy_15.4_eng.pdf;jsessionid=DACF 307B38602BB1BDBDEAFC86D3E5B7? sequence=1 [Accessed 13 Jan 2021].

28 World Food Program. WFP's response to the Ebola outbreak in DRC, 2018. Available: https://reliefweb.int/report/democratic-republiccongo/wfp-s-response-ebola-outbreak-drc-19-november-2018 [Accessed 16 Oct 2020].

29 World Health Organization. Assessment report of the global vaccine action plan strategic Advisory group of experts on immunization, 2018. Available: https://www.who.int/immunization/global_vaccine_ action_plan/SAGE_GVAP_Assessment_Report_2018_EN.pdf [Accessed 14 Jan 2021].

30 Democratic Republic of Congo. Demographic health survey 2013-14, 2014. Available: https://dhsprogram.com/pubs/pdf/SR218/SR218.e. pdf [Accessed 13 Nov 2020].

31 United Nations Children's Fund. Declining vaccination rates in the Democratic Republic of the Congo could lead to resurgence in deadly diseases, 2020. Available: https://www.unicef.org/pressreleases/declining-vaccination-rates-democratic-republic-congocould-lead-resurgence-deadly [Accessed 14 Jan 2021].

32 Alfonso VH, Bratcher A, Ashbaugh $\mathrm{H}$, et al. Changes in childhood vaccination coverage over time in the Democratic Republic of the Congo. PLoS One 2019;14:e0217426.

33 Di Gennaro F, Marotta C, Locantore P, et al. Malaria and COVID-19: common and different findings. Trop Med Infect Dis 2020;5:141.

34 Darmstadt GL, Bhutta ZA, Cousens S, et al. Evidence-based. Costeffective interventions: how many newborn babies can we save? Lancet 2005;365:977-88.

35 Yerger $\mathrm{P}$, Jalloh M, Coltart CEM, et al. Barriers to maternal health services during the Ebola outbreak in three West African countries: a literature review. BMJ Glob Health 2020;5:e002974.

36 Smith J. Overcoming the 'tyranny of the urgent': integrating gender into disease outbreak preparedness and response. Gender \& Development 2019;27:355-69.

37 et alCommittee IR, McKay G, Black B. Not all that bleeds is Ebola: how has the DRC Ebola outbreak impacted sexual and reproductive health in North-Kivu, 2019. Available: https://www.rescue.org/sites/ default/files/document/4416/srhebolareport1172020.pdf [Accessed 29 Jan 2021]

38 World Health Organization. Risk communication and community engagement preparedness and readiness framework: Ebola response in the Democratic Republic of Congo in North Kivu, 2018. Available: https://apps.who.int/iris/bitstream/handle/10665/275389/ 9789241514828-eng.pdf?ua=1 [Accessed 27 Oct 2020].

39 United Nations Children's Fund. UNICEF welcomes end of 90-day Ebola surveillance period in eastern DRC and calls for government to maintain lifesaving health services for women and children. Available: https://www.unicef.org/drcongo/en/press-releases/unicef-welcomesend-90-day-ebola-surveillance-period [Accessed 16 Oct 2020].

40 Edmond KM, Zandoh C, Quigley MA, et al. Delayed breastfeeding initiation increases risk of neonatal mortality. Pediatrics 2006;117:e380-6.

41 World Health Organization. Guidelines for the management of pregnant and breastfeeding women in the context of Ebola virus disease, 2020. Available: https://apps.who.int/iris/bitstream/handle/ 10665/330851/9789240001381-eng.pdf [Accessed 13 Jan 2021].

42 Medina-Rivera M, Centeno-Tablante E, Finkelstein JL. Presence of Ebola virus in breast milk and risk of mother-to-child transmission: synthesis of evidence. Ann N Y Acad Sci (published Online First: 28 Oct 2020). 
43 Ververs M, Arya A. Ebola virus disease and breastfeeding: time for attention. The Lancet 2019;394:825.

44 United States Agency for International Development. Overcoming sexual and gender based violence: IMA World Health Ushindi project, 2019. Available: https://www.usaid.gov/faith-and-opportunityinitiatives/success-stories/jun-2019-overcoming-sexual-and-genderbased-violence-ima-world-health-ushindi-project [Accessed $13 \mathrm{Nov}$ 2020].

45 Healio: Infectious Disease. Ebola survivors face health issues long after recovery, 2020. Available: https://www.healio.com/news/ infectious-disease/20200917/ebola-survivors-face-health-issueslong-after-recovery [Accessed 14 Jan 2021].

46 Buysse DJ, Reynolds CF, Monk TH, et al. The Pittsburgh sleep quality index: a new instrument for psychiatric practice and research. Psychiatry Res 1989;28:193-213.

47 Snell WE, Gum S, Shuck RL, et al. The clinical anger scale: preliminary reliability and validity. J Clin Psychol 1995;51:215-26.

48 Busch FN. Anger and depression. Adv. psychiatr. treat 2009;15:271-8

49 Judd LL, Schettler PJ, Coryell W, et al. Overt irritability/anger in unipolar major depressive episodes: past and current characteristics and implications for long-term course. JAMA Psychiatry 2013;70:1171-80.

50 Luutonen S. Anger and depression--theoretical and clinical considerations. Nord J Psychiatry 2007;61:246-51.

51 Galovski TE, Elwood LS, Blain LM, et al. Changes in anger in relationship to responsivity to PTSD treatment. Psychol Trauma 2014;6:56-64.

52 Aragón-Arreola JF, Moreno-Villegas CA, Armienta-Rojas DA, et al. An insight of sleep disorders in Africa. eNeurologicalSci 2016;3:37-40.
53 Stranges S, Tigbe W, Gómez-Olivé FX, et al. Sleep problems: an emerging global epidemic? findings from the indepth WHO-SAGE study among more than 40,000 older adults from 8 countries across Africa and Asia. Sleep 2012;35:1173-81.

54 Clark DV, Kibuuka H, Millard M, et al. Long-term sequelae after Ebola virus disease in Bundibugyo, Uganda: a retrospective cohort study. Lancet Infect Dis 2015;15:905-12.

55 Wilson HW, Amo-Addae M, Kenu E, et al. Post-Ebola syndrome among Ebola virus disease survivors in Montserrado County, Liberia 2016. Biomed Res Int 2018;2018:1909410.

56 Lord C, Sekerovic Z, Carrier J. Sleep regulation and sex hormones exposure in men and women across adulthood. Pathol Biol 2014;62:302-10.

57 Berhanu H, Mossie A, Tadesse S, et al. Prevalence and associated factors of sleep quality among adults in Jimma town, Southwest Ethiopia: a community-based cross-sectional study. Sleep Disord 2018;2018:1-10.

58 Turner S, Mota N, Bolton J, et al. Self-Medication with alcohol or drugs for mood and anxiety disorders: a narrative review of the epidemiological literature. Depress Anxiety 2018;35:851-60.

59 McIntyre RS, Rosenbluth M, Ramasubbu R, et al. Managing medical and psychiatric comorbidity in individuals with major depressive disorder and bipolar disorder. Ann Clin Psychiatry 2012;24:163-9.

60 World Health Organization. Psychological first aid during Ebola virus disease outbreaks, 2014. Available: https://apps.who.int/ iris/bitstream/handle/10665/131682/9789241548847_eng.pdf; jsessionid=D8D5A3A6FF9D1F86A2BC841CF5DF2293? sequence $=1$ [Accessed 31 Jan 2021]. 